\title{
Does the Distribution of Public Good Matter for Tax Compliance Behavior?
}

\author{
Mengdi Chen and Ya Zhou* \\ School of Systems Science, Beijing Normal University, Beijing, China \\ ${ }^{*}$ Corresponding Author
}

\begin{abstract}
The research of tax suggest that the mechanism how public good return has an important influence on tax compliance. The taxpayers pay taxes to the government to purchase public good and services. Therefore, we considered that the taxpayer's decision-making process would be affected by the satisfaction of the public good allocation. We conduct a laboratory experiment and analyze how the public good return influences tax compliance behavior by applying high, low, linear high and linear low return mechanisms. The results indicate that a certain amount of public good return can improve tax compliance. First, compared with no public good, taxpayers will be more honest on income declare process when receiving the public good. And there is an inverse u-shaped relationship between public good return and tax compliance.
\end{abstract}

Keywords—public good return; tax compliance; regression

\section{INTRODUCTION}

It is a popular area of tax theory to analyze which factors affect the people's tax compliance and how these factors influence tax compliance. For example, in Allingham and Sandmo's research, they find a higher audit probability or a higher penalty can make taxpayers to declare their income more truthfully [1]. Feld and Weck-Hannemann's research indicates that if individuals participate in the decision process [2], the level of tax evasion decreases [3]. Fortin and Spicer' $s$ experiments show that if taxpayers think the tax system relatively fair, they declare their income more truthfully [4][5]. Chang-Gyun Park and Torgler's researches find that if individuals are persuaded by the tax authorities for tax purpose before they declare their income, the tax compliance can increase significantly [6][7]. For more overviews on determinants of tax compliance, you can refer to Torgler and Hofmann's results [8][9].

In general, the research on the traditional factors of tax payment, such as auditing, punishment and tax rate are abundant [10]. The existing research on tax evasion has been based on the experimental method combining psychology and sociology theory to analyze the impact of environment, mechanism and other behavioral factors on taxpayers' decision-making [11][12]. In modern tax theory, the process of taxpaying is the exchange process of buying public good and public services provided from the government. Individuals pay tax to purchase public good and service from the government. Feld and Kirchgassner point out that there is a strong connection among tax, public service and high tax awareness [13]. In this paper, we contribute to tax literature by conducting experiments to analyze how public good return affect individual's sense of equity and tax compliance.
We defined tax compliance rate as number of the subjects who declare their actual income as a percentage of total. All results indicate that a certain number of public good return has a positive effect on tax compliance. However, high public good return is less beneficial to tax compliance compared to low public good return.

\section{THE LABORATORY EXPERIMENT}

Our experiment consists of two practice rounds and twenty payoff-relevant rounds. In each round, Subjects will receive a fixed income of 1,000 virtual currency. Every subject's task is to declare the income. The declared income $z_{i}$ can be lower than the true income, but not higher. Dependent on the declared income, the subjects pay a tax with a tax rate $\mathrm{t}(\mathrm{t}=0.4)$.

A tax declaration is audited with probability $p(p=0.2)$ which is exogenously given and identical for all subjects across all treatments. In case of an observed tax evasion, the subject should pay a penalty which is $\mathrm{f}$ times the evaded tax $(\mathrm{f}=1.5)$. There are three cases maybe happen: (1) no audit, (2) audit and no tax evasion is disclosed, (3) audit and tax evasion is disclosed. The total payment $\mathrm{Ti}$ (include penalty) is:

- $\quad$ No audit: $T_{i}=t \bullet Z_{i}$

- $\quad$ Audit and no tax evasion: $T_{i}=1000 t$

- $\quad$ Audit and tax evasion: $T_{i}=1000 t+f t\left(1000-z_{i}\right)$

After the tax declaration decision, the tax revenue collected from all group members will become public good. The government distributes public good to the group members. In our experiment, we divide subjects into high public good return group and low public good return group. In first 10 rounds, all subjects declare their income while receiving no public good. In next 10 rounds, subjects declare their income while receiving high and low public good. The distribution mechanism of public good differs across four treatments:

- $\quad$ 1a. High public good return group: Each group member receives $\mathrm{Ri}=400$ from distribution.

- $\quad$ b. Linear high public good return group: Each group member receives $R_{i}=\frac{e}{N} \sum_{j=1}^{N} A_{i j}$ from distribution of which $\mathrm{e}=1$, Aij is the actual tax that subject $\mathrm{j}$ in the round i have payed (excluding the penalty).

- $\quad 2$ a. Low public good return group: Each group member receives $R i=100$ from distribution. 
- $\quad$ b. Linear low public good return group: Each group member receives $R_{i}=\frac{e}{N} \sum_{j=1}^{N} A_{i j}$ from distribution of which $\mathrm{e}=1 / 3$.

In our view, when $\mathrm{e}=1$, the government perfectly realized the transformation of tax revenue and public good distribution, and when $\mathrm{e}=1 / 3$, the government partially realized this transformation. Fixed return of public good is based on real life, when the taxpayer enough, public good return is independent of the amount of their income and tax. In other word, each taxpayer's tax evasion behavior almost does not affect the overall supply of public good. But when the number of taxpayer is small, the non-fixed public good return is more appropriate.

Consequently, the total payoff $\pi_{i}$ is determined in each round as follows:

$$
\pi_{i}=1000-T_{i}+R_{i}
$$

At the end of the experiment, one round of income was selected randomly from the first 10 rounds and another one round of income was selected randomly from the last 10 rounds, and the mean of the two incomes was used as the basis for the experimental reward.

\section{HYPOTHESES}

\section{A. Optimal Behavior of Risk-Neutral and Self-Interested Individuals}

We derive the optimal declaration decision under the assumptions that each subject is risk neutral and only selfinterested. We can show that under these assumptions an individual will not declare any income.

\section{B. Behavioral Expectation}

The taxpayers pay taxes to the government to purchase public good and services. Therefore, we considered that the taxpayer's decision-making process would be affected by the satisfaction of the public good allocation. When taxpayers feel that the tax system is fair, they will be more honest in their income declaration. Chang-Gyun Park and Torgler's researches find that if individuals are persuaded by the tax authorities for tax purpose, the tax compliance can increase significantly. Thus, the trust of taxpayers in the tax authority are positively related to the tax compliance rate. When the government distributed public good to taxpayers properly, the trust of taxpayers in the tax authority will improve. Then higher tax compliance rate is expected. There are three hypotheses as follows:

- Hypothesis 1: Compared with no public good, taxpayers will be more honest on income declare process when receiving the public good.

- Hypothesis 2: Subjects declare more income in the high public good return group than in the low public good return group.

- Hypothesis 3: Taxpayers who believe that fairness is important declare income more honest when receiving the public good than those who think that fairness is not important.

\section{EXPERIMENTAL PROTOCOL}

The fixed public good return experiment was conducted in Beijing Normal University (BNU) in July 2011. 51 subjects from different university participated in our experiment. The experiment was programmed using z-tree. The experiment has a total of 22 rounds, the first two rounds are practice rounds. Subjects can get 1000 virtual currency as the gross income in each round, the tax rate is $40 \%$, the penalty rate is $150 \%$, the audit rate is $20 \%$, and these variables are fixed in all rounds. Subjects were divided into high public good return group (25 subjects) and low public good return group (26 subjects). In the first ten rounds, both groups receive no public good. In the last ten rounds, subjects in the high public good group was informed that they would receive 400 public good return per person in each round, while subjects in the low public good group were informed that they would receive 100 public good per person in each round.

The linear public good return experiment was conducted in PANJIN Vocational \& Technical College in November 2011. 67 subjects participated in our experiment, 39 subjects are from school, others are from society. The experiment was programmed using z-tree. The conditions are consistent with the previous experiment. Subjects were also divided into high public good return group (34 subjects) and low public good return group (33 subjects). Each round we audited 7 subjects from each group. In the first ten rounds, both groups receive no public good. In the last ten rounds, all subjects were informed that they would get some public good return per person after audit in each round. Public good return in each round were calculated by following formula: $R_{i}=\frac{e}{N} \sum_{j=1}^{N} A_{i j}$.Where i represents round, e is the coefficient of public good(e=1/3 in low public good return group, $\mathrm{e}=1$ in high public good return group), $\mathrm{N}$ is number of total subjects in a group, $\boldsymbol{A}_{\boldsymbol{i} \boldsymbol{j}}$ is the actual tax that subject $\mathrm{j}$ in the round i have payed (excluding the penalty).

TABLE I presents summary statistics for subjects by different treatments in this experiment from a post-experiment questionnaire. The subjects in the HUE group think the fairness is important, and subjects in the LUE group think the fairness is not important.

TABLE I. SUMMARY STATISTICS FOR SUBJECTS BY DIFFERENT TREATMENTS

\begin{tabular}{lccccc}
\hline \multicolumn{5}{c}{ Summary statistics for subjects by different treatments } \\
\hline \multirow{2}{*}{ Gender } & $\mathbf{1 0 0}$ & $\mathbf{4 0 0}$ & $\boldsymbol{e}=\mathbf{1 / 3}$ & $\boldsymbol{e}=\mathbf{1}$ \\
\hline \multirow{4}{*}{ Risk attitude } & Man & 15 & 14 & 21 & 18 \\
& Woman & 11 & 11 & 12 & 16 \\
& Risk Lover & 13 & 10 & 17 & 21 \\
& Risk evader & 13 & 15 & 16 & 13 \\
& LUE & 18 & 13 & 8 & 14 \\
& HUE & 8 & 12 & 25 & 20 \\
\hline
\end{tabular}

V. RESUlts

\section{A. Income Declaration}

FIGURE I shows a negative relationship between declared income and period. As the experiment is carried out, the reported income is declining. Subjects become wiser as they learn more 
about the experiment, which is the proof that each subject is selfinterested.

\section{B. Tax Compliance Behavior}

TABLE II depicts descriptive statistics for our tax compliance measure separated for each treatment. We observe that the declared income is lowest when subjects do not get public good (453). And the tax compliance rate is the lowest (17\%). When subjects receive the public good, the declared income and tax compliance can be higher compared with no public good. We can see the tax compliance rate is highest when subjects receive linear low public good (35\%). However, TABLE II shows higher public good return do not improve the declared income and tax compliance no matter fixed public good return or linear public good return. FIGURE II clearly depicts that subjects will be more honest when receiving public good. By using the t-test, we find that the declared income difference between the no public good return and public good return is statistically significant at a 5\%-level with a p-value of 0.0012 . When subjects get fixed public good, the declared income difference between high public good return group (400) and low public good return group (100) is also statistically significant at a $5 \%$-level with a p-value of 0.003 . However, when subjects get linear public good, the declared income difference between high public good return group $(\mathrm{e}=1)$ and low public good return group $(e=1 / 3)$ is not significant. In conclusion, we observe the declared income and tax compliance can be higher compared with no public good, when subjects receive the public good. But higher public good return do not improve the declared income and tax compliance from our experimental data. We speculate there is an inverse $u$-shaped relationship between public good return and tax compliance.

According to equity theory, when individuals find themselves in an unfair relationship, they will become depressed and try to change their own or each other's income or investment, in order to rebuild the sense of fairness. Therefore, if the subjects think that fairness is not important, when receiving public good, his decision is no difference compared with no public good return. And if they think fairness is important, and they feel that it is more fair to give them a public return, they will increase their declared income.

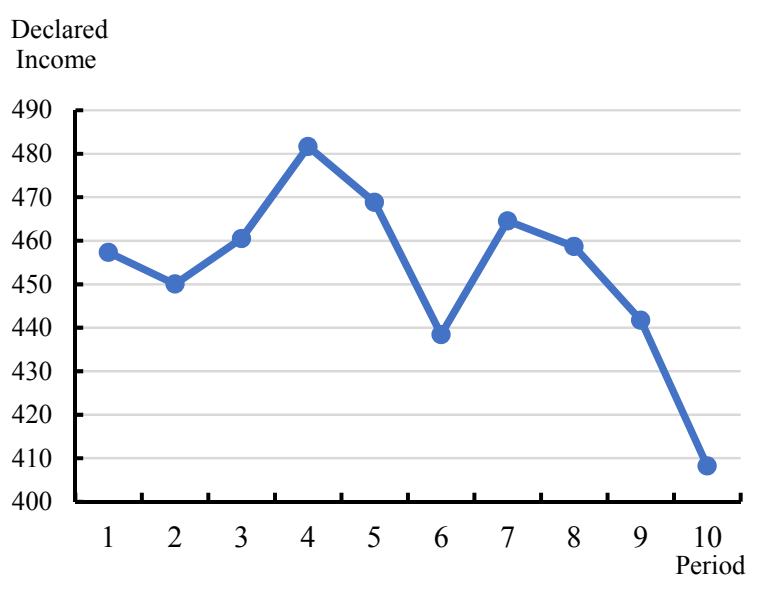

FIGURE I. DECLARED INCOME ON AVERAGE ALL TREATMENTS OVER TIME

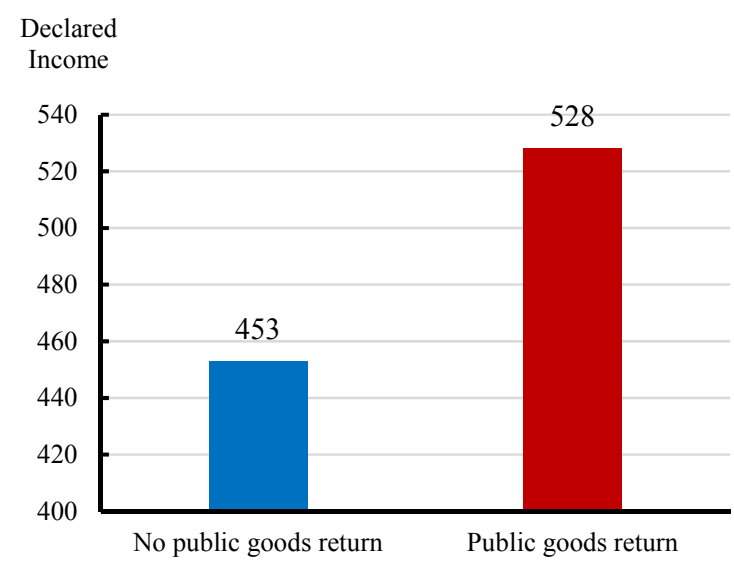

FIGURE II. NO PUBLIC GOOD RETURN AND PUBLIC GOOD RETURN'S INCOME DECLARED

TABLE II. DECLARED INCOME

\begin{tabular}{lc|cccc}
\hline \multicolumn{5}{c}{ Declared Income } \\
\hline & $\begin{array}{c}\text { No Public } \\
\text { Good }\end{array}$ & \multicolumn{4}{c}{ Public Good } \\
\hline & $\boldsymbol{0}$ & $\mathbf{1 0 0}$ & $\mathbf{4 0 0}$ & $\boldsymbol{e}=\mathbf{1 / 3}$ & $\boldsymbol{e}=\mathbf{1}$ \\
\hline Mean & 453 & 599 & 468 & 549 & 498 \\
Median & 500 & 710 & 578 & 600 & 500 \\
Standard deviation & 390 & 362 & 402 & 428 & 406 \\
No.of observations & 67 & 26 & 25 & 34 & 33 \\
tax compliance rate & $17 \%$ & $22 \%$ & $19 \%$ & $35 \%$ & $24 \%$ \\
\hline
\end{tabular}

From TABLE III, we observe that the declared income in the LUE group is lowest when subjects get 400 public good (384). Also, the tax compliance rate is the lowest $(7 \%)$.We can see when subjects receive the public good, their tax compliance can be decrease. Subjects in the LUE group, when receiving public good, their decision is no difference compared with no public good return. However, in the HUE group, the declared income and tax compliance can be higher compared with no public good. We can see the tax compliance rate is highest when subjects receive linear low public good (41\%). TABLE III shows higher public good return do not improve the declared income and tax compliance. Besides, compared with the LUE group, the declared income and tax compliance in the HUE group can be higher when subjects get public good return. FIGURE III clearly depicts that subjects in the HUE group will be more honest when receiving public good. By using the t-test, we find that the declared income difference between the HUE group and the LUE group is statistically significant at a $5 \%$-level with a pvalue of 0.019 . In conclusion, we observe the declared income and tax compliance can be higher in the HUE group. That is, taxpayers who believe that fairness is important declare income more honest when receiving the public good than those who think that fairness is not important.

In our experiment, when the subject's declared income was 1000 , we deem that the subject followed the tax rules. Otherwise, the subject has not complied the tax rules. FIGURE IV and FIGURE V shows tax compliance rate in the HUE and LUE group under different treatment. We can find that the compliance rate of the HUE group is higher than LUE group. FIGURE IV shows that the compliance rate under no public good treatment 
generally lower than the others. Besides, the compliance rate under linear high public good return treatment generally higher than the others. However, in the FIGURE V, the different of compliance rate is not significant between no public good return and with public good return. Therefore, if the subjects think that fairness is not important, when receiving public good, his decision is no difference compared with no public good return. And if they think fairness is important, and they feel that it is more fair to give them a public return, they will increase their declared income.

TABLE III. DECLARED INCOME

\begin{tabular}{cccccc|ccccc}
\hline & \multicolumn{3}{c|}{ LUE } & \multicolumn{5}{c}{ HUE } \\
\hline & $\mathbf{0}$ & $\mathbf{1 0 0}$ & $\mathbf{4 0 0}$ & $\boldsymbol{e}=\mathbf{1 / 3}$ & $\boldsymbol{e}=\mathbf{1}$ & $\mathbf{0}$ & $\mathbf{1 0 0}$ & $\mathbf{4 0 0}$ & $\boldsymbol{e}=\mathbf{1 / 3}$ & $\boldsymbol{e}=\mathbf{1}$ \\
\hline Mean & 421 & 587 & 384 & 476 & 483 & 469 & 596 & 559 & 572 & 508 \\
$\begin{array}{c}\text { Median } \\
\text { Standard } \\
\text { deviation } \\
\text { No. of } \\
\text { observations }\end{array}$ & 300 & 650 & 250 & 275 & 500 & 500 & 735 & 700 & 700 & 500 \\
$\begin{array}{c}\text { tax } \\
\text { compliance }\end{array}$ & $17 \%$ & $17 \%$ & 394 & 475 & 408 & 383 & 397 & 392 & 410 & 405 \\
\hline & 18 & 13 & 8 & 14 & 45 & 8 & 12 & 25 & 20 \\
\hline
\end{tabular}

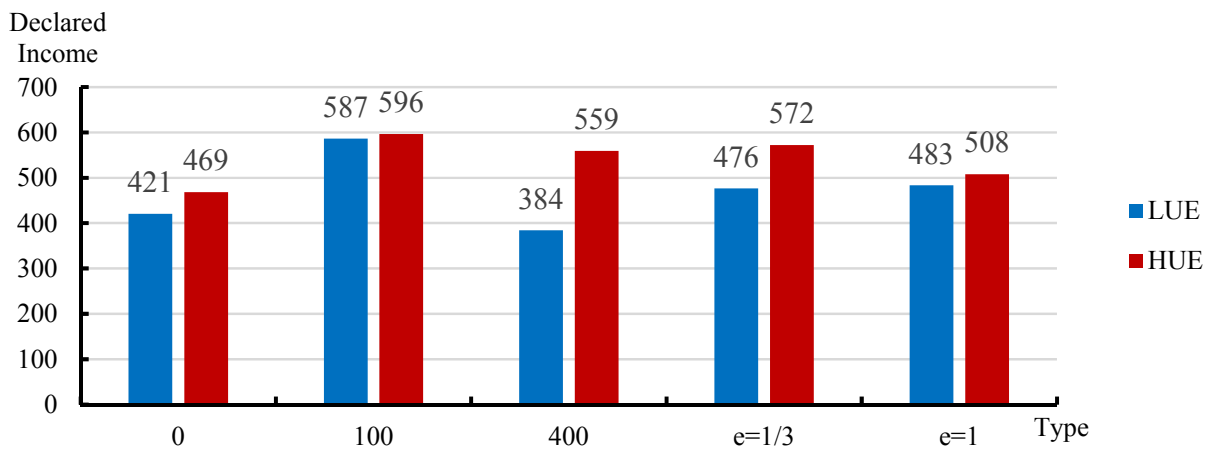

FIGURE III. DECLARED INCOME OF THE HUE AND LUE

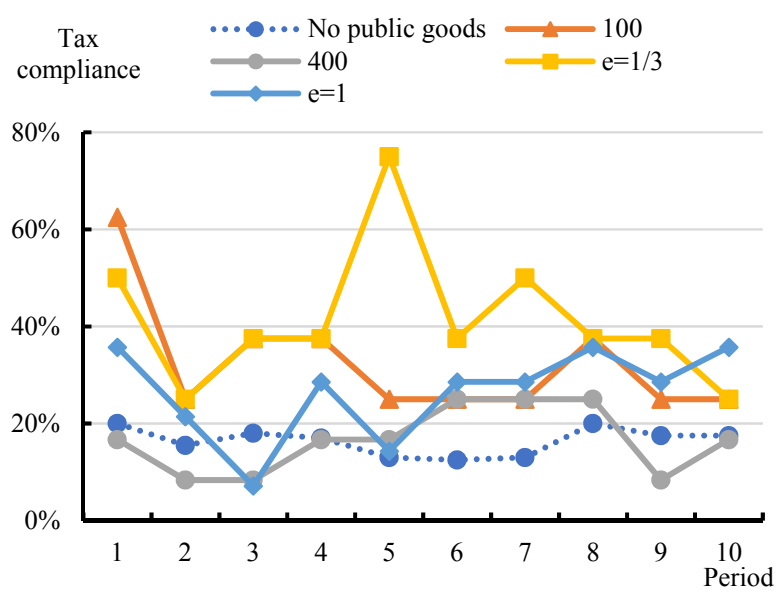

FIGURE IV. TAX COMPLIANCE OF THE HUE

In the following content, we analyze how public good return and the tax compliance behavior interact. We use Tobit regressions with the declared rate as the dependent variable. If a

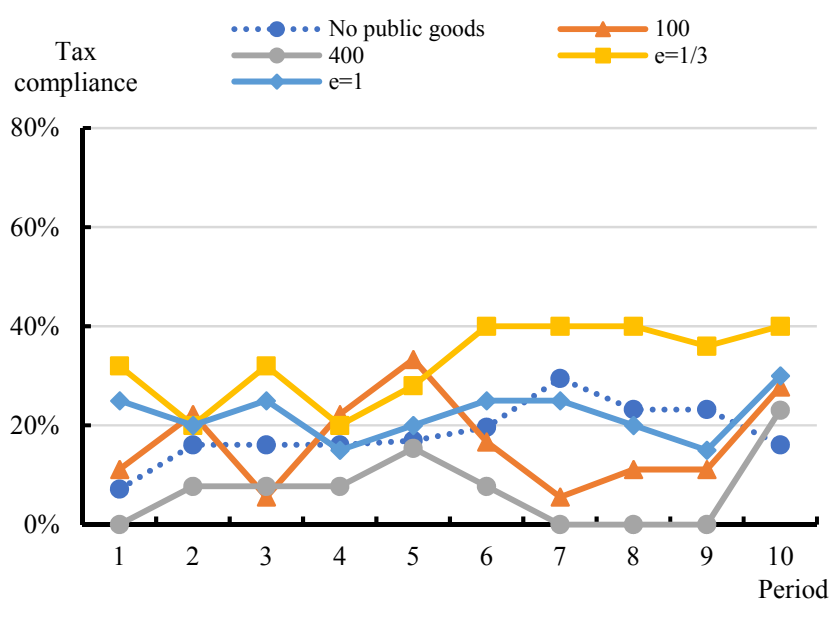

FIGURE V. TAX COMPLIANCE OF THE LUE

subject is in Low (High/ Linear high/ Linear low) public good return group, the Low (High/ Linear high/ Linear low) public good return group dummy take the value of 1 , otherwise 0 . No 
public good return group serves as the default, so the coefficient of each group dummy measures the difference between the current group and no public good return group. We use Tobit regressions in the following analyses which can be written as below.

$$
\phi_{i g}=\alpha+\beta \cdot \text { Treat }_{g}+\phi \cdot \mathrm{X}_{i g}+\epsilon_{i g}
$$

Where subscripts indicate a subject $\mathrm{i}$ in group $\mathrm{g}=1,2,3,4,5$ (with $\mathrm{g}=1$ :no public good; $\mathrm{g}=2$ low public good; $\mathrm{g}=3$ high public good; $g=4$ linear low public good; $g=5$ linear high public good). $\phi_{i g}$ is the declared share of income that subject i reported. $\beta$ is the coefficient of the dummy variables for the treatments. The model also includes control variables(captured in $\mathrm{X}_{i g}$ ): "sex"(male=1, female=2); "age"; "equity"(a subject sense of fairness when received public good, measured on an 7-point scale where $1=$ feeling unfair and $7=$ feeling fair);"use of equity"(a subject's willingness of using equity in making tax decision, measured on an 7-point scale where 1=unwilling to use and 7=willing to use); "tax moral"(a subject's willingness to declare tax truthfully, measured on an 7-point scale where $1=$ unwilling to do and 7=willing to do); "guilty"(describes how much a subject feels shame about tax evasion when not audited, measured on an 7-point scale where $1=$ feel shame and 7=don't feel shame); "guilty shame"(describes how much a subject feels shame about tax evasion when audited, measured on an 7-point scale where $1=$ don't feel shame about tax evasion and $7=$ feel shame about tax evasion); "last period audit"( 1 if a subject was audited in the previous round, 0 otherwise). The Tobit regressions' results are shown in the TABLE IV.

Compared to model1, model 2 includes control variables and model 3 includes control variables and last period audit. TABLE IV shows that the low (100) and linear low public good return $(\mathrm{e}=1 / 3)$ treatments are positive for declared income. However, in model1, the coefficients of high public good return (400) is negative, and in model 2 and model 3 , both coefficients of high public good return and linear high public good return treatments are negative, which means there is an inverse u-shaped relationship between public good return and tax compliance. Table 4 shows that the estimated coefficients of four treatments confirmed previous analysis: low public good return can improve tax compliance compared to no public good return while high public good return group's tax compliance is less compared to no public good return group. In models 2 and 3, these results remain true. From the regression results, we also find the effect of high public good return group's dummy variable seems to be much stronger than the low public good return group's dummy variable, which indicates that low public good return has a larger positive influence in tax compliance compared to the high public good return. Applying Wald test after regression, we find the coefficients of the different treatments of public good return are significant at a $1 \%$-level except linear high public good return.

With respect to the control variables, we can get following conclusions. The coefficient of "guilty" is negative, which means that subjects who are more willing to evade taxes are less tax compliant. However, the coefficients of "sex", "age", "use of equity", "equity", "tax moral" and "guilty shame" are all positive, which indicates that older woman are more honest when declared income. Besides, the subject's sense of equity can influence his decision. Tax compliance is higher when subjects feel equitable. Furthermore, when subjects feel more shame about tax evasion, they will be more honest. From Model3, we also find the coefficient of the "last period audit" is negative, which indicates that individuals are less compliant with the tax law after they were audited.

From above analysis, we can conclude that in both fixed and linear public good return experiments, there is an inverse ushaped relationship between public good return and tax compliance. A certain amount of public good return can make subjects to declare their income more truthfully. In particular, up to a certain level, tax compliance increases with the public good return. Above this level, however, tax compliance decreases with the public good return. From the experimental data, low public good return has a larger positive influence in tax compliant compared to the high public good return. Which means low public good return can make subjects to declare their income more truthfully compared to high public good return.

TABLE IV. TOBIT REGRESSIONS: EFFECTS OF PUBLIC GOOD ON COMPLIANCE

\begin{tabular}{|c|c|c|c|}
\hline & Model1 & Model2 & Model3 \\
\hline \multicolumn{4}{|l|}{ Reference: No Public Good } \\
\hline \multirow[t]{2}{*}{ Low Public Good (100) } & $0.173^{* * *}$ & $0.241^{* * *}$ & $0.245^{* * *}$ \\
\hline & $(0.048)$ & $(0.048)$ & $(0.048)$ \\
\hline \multirow[t]{2}{*}{ High Public Good (400) } & $-0.152^{* * *}$ & $-0.159^{* * *}$ & $-0.155^{* * *}$ \\
\hline & $(0.049)$ & $(0.049)$ & $(0.049)$ \\
\hline \multirow[t]{2}{*}{ Linear Low PG(e=1/3) } & $0.143^{* * *}$ & $0.122^{* * *}$ & $0.125^{* * *}$ \\
\hline & $(0.044)$ & $(0.044)$ & $(0.044)$ \\
\hline Linear High & 0.028 & -0.009 & -0.014 \\
\hline PG $(e=1)$ & $(0.043)$ & $(0.043)$ & $(0.043)$ \\
\hline \multirow[t]{2}{*}{ Sex } & & $0.098^{* * *}$ & $0.097^{* * *}$ \\
\hline & & $(0.030)$ & $(0.030)$ \\
\hline \multirow[t]{2}{*}{ Age } & & $0.016^{* * *}$ & $0.015^{* * *}$ \\
\hline & & $(0.002)$ & $(0.002)$ \\
\hline \multirow[t]{2}{*}{ Equity } & & 0.012 & 0.012 \\
\hline & & $(0.007)$ & $(0.007)$ \\
\hline \multirow[t]{2}{*}{ Use of equity } & & $0.026^{* * *}$ & $0.026^{* * *}$ \\
\hline & & $(0.007)$ & $(0.007)$ \\
\hline \multirow[t]{2}{*}{ Tax moral } & & $0.062^{* * *}$ & $0.062^{* * *}$ \\
\hline & & $(0.010)$ & $(0.010)$ \\
\hline \multirow[t]{2}{*}{ Guilty } & & $-0.044^{* * *}$ & $-0.044^{* * *}$ \\
\hline & & $(0.011)$ & $(0.011)$ \\
\hline \multirow[t]{2}{*}{ Guilty shame } & & $0.045^{* * *}$ & $0.045^{* * *}$ \\
\hline & & $(0.010)$ & $(0.010)$ \\
\hline \multirow[t]{2}{*}{ Last period Audit } & & & -0.036 \\
\hline & & & $(0.039)$ \\
\hline \multirow[t]{2}{*}{ constant } & $0.468^{* * *}$ & $-0.426^{* * *}$ & $-0.418^{* * *}$ \\
\hline & $(0.020)$ & $(0.093)$ & $(0.093)$ \\
\hline $\mathbf{N}$ & 2360 & 2360 & 2360 \\
\hline Pseudo R2 & 0.008 & 0.045 & 0.045 \\
\hline
\end{tabular}

Notes: Tobit regressions based on equation (1). Standard errors in parentheses clustered by individuals. Estimates are based on a sample of 118 individuals and 20 periods. Significant levels are $*<0.10, * *<0.05, * * *<0.01$. Dependent variable: Declared rate defined as income reported for tax purposes divided by gross income. Independent variables of interest are the dummy variables for the treatment groups "Low Public Good", "High Public Good", "Linear Low Public Good(e=1/3)" and "Linear High Public Good(e=1)". Coe cients of interest are relative to the omitted treatment group "No Public Good" (in "constant"). 


\section{CONCLUSION}

We conduct a laboratory experiment and analyze how the public good return influences tax compliance behavior by applying high, low, linear high and linear low return mechanisms. In our experiment, we divide subjects into high public good return group and low public good return group. In first 10 rounds, all subjects declare their income while receiving no public good. In next 10 rounds, subjects declare their income while receiving high or low public good. The distribution mechanism of public good differs across four treatments: In the high and low public good return group, each group member receives fixed public good from distribution. And in the linear high and linear low public good return group, each group member receives public good related to other subjects' choices. It can be expected that subjects with a relatively high public good perceive the tax mechanism as more positive than subjects with a low or even no public good. As a consequence, we conjecture that these subjects reveal higher tax compliance rate than low or even no public good. Taxpayers who believe that fairness is important declare income more honest when receiving the public good than those who think that fairness is not important. Furthermore, we run Tobit regressions with the declared share of income as the dependent variable.

The results indicate that in both fixed and linear public good return experiments, a certain amount of public good return can make subjects to declare their income more truthfully. First, compared with no public good, taxpayers will be more honest on income declare process when receiving the public good. In addition, taxpayers who believe that fairness is important declare income more honest than those who think that fairness is not important. However, the effect of different public good distribution on taxpayers' behavior is not significant. Besides, high public good do not increase tax compliance compared with low public good. Inversely, low public good return can make subjects to declare their income more truthfully compared to high public good return. In addition, there is an inverse $\mathrm{u}$-shaped relationship between public good return and tax compliance. In particular, up to a certain level, tax compliance increases with the public good return. Above this level, however, tax compliance decreases with the public good return.

Obviously, our conclusions contain limitations concerning the implications of our findings for the real decision-making of taxpayers. First of all, our experimental setting is rather artificial and notional. We consider many variables as constants, such as income and tax rate. Besides, our experiment samples are not enough, which may cause fault in the experimental results. Futhermore, our treatments of public good return contain limitations. We only compared high public good return and low public good return. And in the linear public good return treatments, the experimental is idealized. For example, when $\mathrm{e}=1$, all tax revenue became public good and distributed to the subjects. Such a situation may not occur in the real society. However, we think that our experimental design is an appropriate approach for this analysis.

\section{ACKNOWLEDGMENT}

I want to take this chance to thanks to my tutor----Ya Zhou. In the process of composing this paper, he gives me many academic and constructive advices, and helps me to correct my paper. His keen and vigorous academic observation enlightens me not only in this thesis but also in my future study.

\section{REFERENCES}

[1] Allingham, M. G., Sandmo, A. (1972). Income tax evasion: A theoretical analysis[J]. Journal of Public Economics, 1, 323-338.

[2] Feld, L. P., Tyran, J.-R. (2002). Tax evasion and voting: An experiment analysis[J]. Kyklos, 55, 197-222.

[3] Weck-Hannemann,H.Pommerehne,W.W.(1989).Einkommensteuerhinterziehung in der Schweiz: Eine empirische Analyse [J]. Swiss Journal of Economics and Statistics, 125, 515-556.

[4] Fortin, B., Lacroix, G., Villeval, M.-C. (2007). Tax evasion and social interactions[J]. Journal of Public Economics, 10,107-116.

[5] Spicer, M.W., Becker, L. A. (1980). Fiscal inequity and tax evasion: An experimental approach[J]. National Tax Journal, 33, 171-175.

[6] Park C. G., Hyun K. Examining the determinants of tax compliance by experimental data: a case of Korea [J]. Journal of Policy Modeling, 2003, 25(8): 673-684.

[7] Torgler B. Moral suasion: An alternative tax policy strategy? Evidence from a controlled field experiment in Switzerland [J]. Economics of Governance, 2004,5(3):235-253.

[8] Torgler, B. (2002). Speaking to theorists and searching for facts: Tax moral and tax compliance in experiments[J]. Journal of Economic Surveys, 16,657-683.

[9] Hofmann, E., Hoelzl, E., Kirchler, E. (2008). Preconditions of voluntary tax compliance: Knowledge and evaluation of taxation, norms, fairness, and motivation to cooperate[J]. Journal of Psychology, 216,209-217.

[10] Frey, B.S. Not Just for the Money. An Economic Theory of Personal Motivation [J]. Economic Affairs, 1998,183(3):60-63.

[11] Alm, J., Torgler, B. Culture differences and tax moral in the United States and in Europe [J]. Journal of Economic Psychology, 2006,27(2):224-246.

[12] Torgler, B. Tax Compliance and Tax Moral: A Theoretical and Empirical Analysis [J]. Journal of Economic Literature, 2009 47(1):198-200.

[13] Feld, L.P. and Kirchgassner, G. Direct democracy, political culture, and the outcome of economic policy: a report on the Swiss experience [J] European Journal of Political Economy, 2000, 16(2):287-306. 